\title{
Simple test to distinguish between surgical and non-surgical pneumoperitoneum in ventilated neonates
}

\author{
P VANHAESEBROUCK, ${ }^{*} \mathrm{~J}$ G LEROY, ${ }^{*} \mathrm{C}$ DE PRAETER,${ }^{*} \mathrm{M}$ PARIJS, $\dagger$ AND M THIERY $\ddagger$ \\ Departments of ${ }^{*}$ Paediatrics and Neonatal Medicine, †Anaesthesia, and $\ddagger$ Obstetrics, University Hospital, \\ Ghent, Belgium
}

SUMmARY A simple and accurate method is described for rapid differentiation of surgical and nonsurgical pneumoperitoneum by measuring the partial pressure of oxygen in intraperitoneal air with a blood gas analyser. Results in five ventilated neonates in whom this distinction was not possible by clinical or radiographic means are presented.

Clinical signs and symptoms with or without radiographic findings usually allow differentiation of pneumoperitoneum resulting from air dissecting transdiaphragmatically from the so called surgical pneumoperitoneum caused by leakage of gas from perforated bowel. ${ }^{1-3}$ In some ventilated infants a clear distinction cannot be made between the two types of pneumoperitoneum using these factors alone, and Chang and Hernandez ${ }^{4}$ suggested a rapid method of differentiation by measuring the oxygen concentration in the intraperitoneal air. We propose a less cumbersome and probably more reliable method.

\section{Patients and methods}

Between January 1985 and March 1988 nine out of 580 ventilated neonates in our neonatal intensive care unit developed radiographic evidence of pneumoperitoneum (table 1). In seven of these (cases 1-7) the pneumoperitoneum was caused by intestinal perforation, whereas in the other two the nonsurgical pneumoperitoneum was the result of dissecting extra-alveolar air.

In four of the seven babies with gastrointestinal pneumoperitoneum (cases 1-4) no alveolar air leak syndrome was present and sufficient clinical or radiographic findings were available for a certain preoperative diagnosis. In the remaining three (cases 5-7) chest radiographs confirmed the presence of pulmonary air leak syndrome (pneumothorax, pneumomediastinum, or interstitial emphysema, or a combination) in association with hyaline membrane disease before the finding of intraperitoneal gas. In these three neonates, as well as in the two babies with pneumoperitoneum of respiratory origin (cases 8 and 9) neither clinical, nor radiographic differentiating features were available

Table 1 Clinical and radiographic findings in nine ventilated newborn infants with pneumoperitoneum

\begin{tabular}{|c|c|c|c|}
\hline Case No & Extra alveolar air & Differentiating features & Postoperative diagnosis \\
\hline 1 & None & Pneumatosis intestinalis & Necrotising enterocolitis \\
\hline 2 & None & $\begin{array}{l}\text { Absence of gastric } \\
\text { air/fluid level }\end{array}$ & Gastric perforation \\
\hline 3 & None & Intraperitoneal air/fluid level & Colon perforation \\
\hline 4 & None & $\begin{array}{l}\text { Perforation of appendix } \\
\text { identified by contrast } \\
\text { examination }\end{array}$ & Neonatal appendicitis \\
\hline 5 & $\begin{array}{l}\text { Bilateral pneumothorax } \\
\text { and pneumomediastinum }\end{array}$ & None & Solitary ileal perforation \\
\hline 6 & $\begin{array}{l}\text { Unilateral pneumothorax, } \\
\text { pneumomediastinum, and } \\
\text { pulmonary interstitial emphysema }\end{array}$ & None & Solitary ileal perforation \\
\hline 7 & $\begin{array}{l}\text { Pneumomediastinum and } \\
\text { pulmonary interstitial emphysema }\end{array}$ & None & Solitary ileal perforation \\
\hline 8 & $\begin{array}{l}\text { Bilateral pneumothorax, } \\
\text { pneumomediastinum, and } \\
\text { pulmonary interstitial emphysema }\end{array}$ & None & No operation \\
\hline 9 & $\begin{array}{l}\text { Bilateral pneumothorax, } \\
\text { pneumomediastinum, and } \\
\text { pulmonary interstitial emphysema }\end{array}$ & None & No operation \\
\hline
\end{tabular}


that permitted specific identification of the origin of the intraperitoneal gas.

The partial pressure of oxygen in the inspired air $\left(\mathrm{PIO}_{2}\right)$ may be calculated when the oxygen concentration in the inspired air $\left(\mathrm{FiO}_{2}\right)$ and barometric pressure (PB) are known: $\mathrm{PIO}_{2}=\mathrm{FiO}_{2} \times(\mathrm{PB}-6 \cdot 25){ }^{5}$ According to the physical laws of Dalton and Henry, partial pressure of oxygen in alveolar gas $\left(\mathrm{PAO}_{2}\right)$ must be less than that of the inspired gas. It may be calculated from the alveolar air equation: $\mathrm{PAO}_{2}=\mathrm{PIO}_{2}-\mathrm{PACO}_{2} / \mathrm{R} \quad(\mathrm{R}=$ respiratory gas exchange ratio $\approx 0 \cdot 8) .{ }^{5}$

In cases 5 to 9 , a 20 gauge Quickcath was inserted into the peritoneal cavity at the right lower quadrant after emptying the urinary bladder. The catheter was attached to a three way stopcock and a $10 \mathrm{ml}$ syringe. An aliquot of intraperitoneal air was aspirated and the stopcock closed before removal of the catheter. Aspirated air was gently introduced into the syringe port of the $\mathrm{pH}$ blood gas analyser (Corning 178, Corning Medical and Scientific) and partial pressure of intraperitoneal oxygen was measured and recorded without removing the syringe until the readout had stabilised (readouts endpoint).

\section{Results}

Table 2 shows the results of the calculated measurements corresponding to the oxygen concentration delivered by the respirator, and the results of the partial pressure of intraperitoneal oxygen measured by the blood gas analyser. In the three infants with surgical pneumoperitoneum (cases 5-7) the partial pressure of oxygen delivered by the ventilator (and the partial pressure of oxygen in the alveolar gas) far exceeded the value of the intraperitoneal oxygen (swallowed room air). In contrast, in the two infants (cases 8 and 9) with ventilator induced pneumoperitoneum, the intraperitoneal oxygen tension far exceeded the maximal pressure of oxygen in room air $(19.85 \mathrm{kPa})$ and reflected clearly the calculated partial pressure of oxygen in alveolar gas deduced from the oxygen concentration delivered by the respirator.

\section{Discussion}

Diagnostic errors in differentiating pneumoperitoneum of intestinal from that of respiratory origin in ventilated neonates have been well documented. ${ }^{1-46}$ Because clinical and radiographic criteria are not always adequate, some infants have been needlessly submitted to surgical intervention, and some others to an unacceptable delay in diagnosis, allowing general peritonitis to develop.

In the event that a clear distinction cannot be made, abdominal paracentesis should be performed in order to measure oxygen concentration in the intraperitoneal gas as suggested by Chang and Hernandez. ${ }^{4}$ We have suggested a less cumbersome method based on measurement of the partial pressure of intraperitoneal oxygen with a blood gas analyser.

\section{References}

${ }^{1}$ Leonidas JC, Hall RT, Rhodes PG, Amoury RA. Pneumoperitoneum in ventilated newborns. Am J Dis Child 1974;128: 677-80.

2 Kaufman RA, Kuhns LR, Poznanski AK. Gastrointestinal perforation without intraperitoneal air-fluid level in neonatal pneumoperitoneum. AJR 1976;127:915-21.

3 Ensing G, Koppe JG, van Putten WJ. Pneumoperitoneum in the newborn. J Pediatr Surg 1974;9:547-50.

4 Chang JHT, Hernandez J. Ventilator-induced pneumoperitoneum-a rapid diagnosis. Pediatrics 1980;66:135-6.

${ }^{5}$ Burgess WR, Chernick V. Pulmonary physiology and the child. In: Burgess WR, Chernick V, eds. Respiratory therapy in newborn infants and children. 2nd ed. Stuttgart: Georg Thieme, 1986:12-8.

${ }^{6}$ Knight PJ, Abdenour G. Pneumoperitoneum in the ventilated neonate: respiratory or gastrointestinal origin? J Pediatr 1981; 98:972-4.

Correspondence to Dr P Vanhaesebrouck, Neonatal Intensive Care Unit, Department of Paediatrics, State University of Ghent De Pintelaan 185, B-9000 Ghent, Belgium.

Accepted 26 May 1988

Table 2 Calculated partial pressure of oxygen in inspired air, partial pressure of oxygen in alveolar gas, and partial pressure of intraperitoneal oxygen measured by blood gas analyser

\begin{tabular}{lllll}
\hline $\begin{array}{l}\text { Case } \\
\text { No }\end{array}$ & $\begin{array}{l}\text { Oxygen concentration } \\
\text { in inspired air }\end{array}$ & $\begin{array}{l}\text { Partial pressure of } \\
\text { oxygen in inspired } \\
\text { air }(\mathrm{kPa})\end{array}$ & $\begin{array}{l}\text { Partial pressure of } \\
\text { oxygen in alveolar } \\
\text { gas }(\mathrm{kPa})\end{array}$ & $\begin{array}{l}\text { Partial pressure of } \\
\text { intraperitoneal oxygen } \\
(\mathrm{kPa})\end{array}$ \\
\hline 5 & $0 \cdot 85$ & $80 \cdot 8$ & $74 \cdot 1$ & $7 \cdot 73$ \\
6 & $0 \cdot 35$ & $33 \cdot 3$ & $26 \cdot 7$ & $6 \cdot 53$ \\
7 & $0 \cdot 65$ & $61 \cdot 75$ & $55 \cdot 0$ & $5 \cdot 60$ \\
8 & $0 \cdot 60$ & $56 \cdot 9$ & $50 \cdot 3$ & 43.33 \\
9 & $0 \cdot 80$ & $76 \cdot 0$ & $69 \cdot 3$ & $66 \cdot 05$
\end{tabular}

Assuming mean barometric pressure of $101.3 \mathrm{kPa}, \mathrm{PACO}_{2}$ of $5.33 \mathrm{kPa}$, and a respiratory gas exchange ratio of $0.8\left(\mathrm{PAO}_{2}=\mathrm{FiO}{ }_{2} \times\right.$ $(101 \cdot 3-6 \cdot 25)-5 \cdot 33 / 0 \cdot 8) .1 \mathrm{~mm} \mathrm{Hg}=0 \cdot 1333 \mathrm{kPa}$. 